$\mathbb{T}$ periodica polytechnica

\author{
Transportation Engineering \\ $37 / 1-2(2009) 45+51$ \\ doi: 10.3311/pp.tr.2009-1-2.08 \\ web: http://www.pp.bme.hu/tr \\ (c) Periodica Polytechnica 2009
}

RESEARCH ARTICLE

\section{Supply chain management practices and their applicability}

Zoltán Bokor

Received 2008-09-03

\begin{abstract}
Supply chain management is a popular concept in business theory. Its research results are widely used in practice, too. The available literature and the accessible project experience make it possible and reasonable to analyse the main principles and outcomes of most preferred new techniques so that additional information are provided for future realisations. This paper aims at taking stock of emerging supply chain management practices with special regard to their practical applicability and drawing conclusions for market actors intending to improve their logistics services.
\end{abstract}

\section{Keywords}

supply chain management $\cdot$ logistics $\cdot$ controlling $\cdot$ information technology

Zoltán Bokor

Department of Transport Economics, BME, Bertalan L. u. 2. H-1111 Budapest, Hungary

e-mail: zbokor@kgazd.bme.hu

\section{Introduction}

During the development of supply chain management (SCM) useful practices have emerged. These practices or management tools aim at enhance supply chain (SC) effectiveness and/or efficiency by introducing new planning, controlling and monitoring methods. The success of their implementation, however, depends on several factors which have to be analysed before making decisions on the application.

The next points give an overview about the most emerging SC reorganisation trends based on the literature and practical experience by adding specific comments on their application possibilities and conditions. The following SCM instruments have been chosen for the examination: integration, risk and demand management, controlling, information technology (IT) support.

\section{Supply chain integration}

Supply chain integration can provide significant advantages - suggest several R\&D projects overall the world. The goal of integration is to improve competitiveness and logistics performance by lower uncertainty, reduced inventory and more flexible responses to customer demand. The tools of SC integration include management and technology procedures aiming to make material and information flows easier.

In the literature SC integration has four key areas: internal, external, technological and holistic/environmental. Internal integration focuses on the business processes within the organisation while external integration examines the interfaces to other organisations or entities. Technological factors cover mainly the availability of proper information technology (IT) instruments. Holistic and environmental elements promote integration through adequate company culture, strategy and communication along the whole service chain. Beside these areas the evolutionary process can be divided into four main stages: baseline, functional, reactive and seamless integration [1.7].

So SC integration can be evaluated by two dimensions: key areas and evolution stages. Table 1 gives an overview of the different integration models using the defined evaluation scheme (reedited from the literature). Of course, this categorisation can not be regarded as absolute one: several combinations of the 
Tab. 1. SC integration models

\begin{tabular}{|c|c|c|c|c|}
\hline dimensions & Baseline & Functional & Reactive & Seamless \\
\hline Internal & $\begin{array}{l}\text { - uncoordinated physical } \\
\text { flows } \\
\text { - high level of multiply stock } \\
\text { - long storage and distribu- } \\
\text { tion } \\
\text { - multiply decision points } \\
\text { - no performance measure- } \\
\text { - no shared operational data }\end{array}$ & $\begin{array}{l}\text { - some coordination within } \\
\text { company } \\
\text { - buffered company func- } \\
\text { tions } \\
\text { - few reduction in lead times } \\
\text { - single decision for each } \\
\text { process } \\
\text { - measuring of delivery and } \\
\text { inventory levels } \\
\text { - data sharing within func- } \\
\text { tions }\end{array}$ & $\begin{array}{l}\text { - coordination within com- } \\
\text { pany } \\
\text { - inventory at company } \\
\text { boundary } \\
\text { - excessive reduction in lead } \\
\text { times } \\
\text { - single decision within com- } \\
\text { pany } \\
\text { - excessive measurement } \\
\text { within company } \\
\text { - data sharing within organi- } \\
\text { sation }\end{array}$ & $\begin{array}{l}\text { - coordination across com- } \\
\text { pany boundary } \\
\text { - minimal, strategic inven- } \\
\text { tory } \\
\text { - minimised lead times in SC } \\
\text { - control of SC from a single } \\
\text { point } \\
\text { - measurement across } \\
\text { chain processes } \\
\text { - data sharing throughout } \\
\text { SC }\end{array}$ \\
\hline
\end{tabular}

\section{External}

- large supplier base, open market

- vendor managed inventory (VMI) not used

- poor customer service

- pure buying

- ad hoc contractual arrangements
- some partnerships with selected suppliers

- VMI in experimental stage

- reactive customer service

- decentralised procurement

- management partnership
- strong relationships, minimised suppliers

- VMI in case of some suppliers

- integration with some major customers

- centralised procurement

- management and operational partnership
- multiple tiers, lasting relationships with suppliers

- VMI with key suppliers

- multiple tiers, lasting relationships with customers

- federal procurement organisation

- multi-level relationship management

\section{Technology}

- no dedicated IT systems

- no transparency of information

- manual data transfer

- separate, incompatible transaction systems
- simple identification systems

- some cross-functional transparency

- PC based data transfer

- integrated resource planning
- identification systems with automated functions

- complete transparency within organisation

- few EDI/Internet links to partners

- intra-company transaction systems with rigid interfaces
- full identification, tracking and tracing throughout SC

- full information transparency in SC

- extensive use of EDI/Internet links within $\mathrm{SC}$

- inter-company transaction systems with flexible interfaces

\begin{tabular}{|c|c|c|c|c|}
\hline Holistic & $\begin{array}{l}\text { - } \text { asset focused SC } \\
\text { - communication within } \\
\text { company only } \\
\text { - no formal lateral organisa- } \\
\text { tion } \\
\text { - organisation with sepa- } \\
\text { rated departments } \\
\text { - no SC strategy } \\
\text { - no key performance indica- } \\
\text { tors (KPI) } \\
\text { - defensive organisational } \\
\text { behaviour }\end{array}$ & $\begin{array}{l}\text { - cost focused SC } \\
\text { - few contact points within } \\
\text { SC } \\
\text { - functional teams } \\
\text { - discrete business func- } \\
\text { tions } \\
\text { - functional SC strategy } \\
\text { - functional KPls } \\
\text { - internal team focused or- } \\
\text { ganisational behaviour }\end{array}$ & $\begin{array}{l}\text { - process cost focused SC } \\
\text { - regular contact at top man- } \\
\text { agement level } \\
\text { - cross-functional teams } \\
\text { - flat organisational struc- } \\
\text { ture } \\
\text { - organisationally aligned } \\
\text { SC strategy } \\
\text { - organisational KPIs } \\
\text { - willingness to improve, } \\
\text { prepared for external } \\
\text { relations }\end{array}$ & $\begin{array}{l}\text { - } \text { customer focused SC } \\
\text { - multiple contact at all man- } \\
\text { agement levels } \\
\text { - teams across the SC } \\
\text { - process oriented organisa- } \\
\text { tion structure } \\
\text { - inter-organisationally } \\
\text { aligned SC strategy } \\
\text { - SC KPIs } \\
\text { - open minded behaviour, } \\
\text { continuous change man- } \\
\text { agement }\end{array}$ \\
\hline
\end{tabular}


described models can exist in practice.

Most inland supply chains can be classified as having mainly baseline integration features. This is the case generally in SME (small and medium sized enterprise) sector. Companies of this cluster have neither SC strategy nor appropriate logistics equipment. Their logistics business is based on an ad hoc basis. However, companies with international activity areas may operate supply chains with higher - functional or reactive - integration levels. And supply chains of multinational organisations can reach even the seamless level as they are integral parts of wide business networks.

Companies with non-integrated supply chains can join other (extensive) logistics service networks or can decide to outsource their logistics activities. Several logistics service providers are ready to undertake these tasks. Most of them are so called third party logistics (3PL) service providers operating as own asset (vehicles, terminals, warehouses, etc.) based company. At the same time the actual trend in Europe is the emergence of $4 \mathrm{PL}$ service providers [5].

4PL providers correspond to the demand of enlarged form of outsourcing where a more extensive span of SC responsibility is transferred to a fourth party. So this kind of logistics providers is an agent consolidating the logistics needs and services of multiple companies. They can play the role of gathering different transport and logistics services into single supply chains of high level - seamless - integration. A 4PL operator is responsible for planning and controlling the whole supply chain while it often does not have its own assets: physical processes are carried out (mainly) by subcontractor 3PL partners having (mainly) long term service contracts.

The 4PL is a coordinator making advantages of economies of scale and synergies furthermore it contributes to the synchronisation of different transactions. The major enabling force of its business activity is the wider use of information and communication technology (ICT) tools supporting data sharing and open platforms for SC members (see later).

As mentioned before logistics providers are generally 3PL actors. However, some of them tend to extend their fields of activities to broader networks. At the same time they build closer partnerships with their customers as well as subcontractors. Nevertheless, these operators still have and use their own assets beside coordination so they could be defined as " $3,5 \mathrm{PL}$ " service providers.

\section{Risk management in supply chains}

Companies operating supply chains are facing different kinds of risks. The problems arising may cause mismatches in supply and demand or higher operation costs, etc. The main forms of SC risks can be categorised as follows: supply, process and demand risks. Supply risks can be derived from the costs and commitment of suppliers. Process risks come from uncertain capacities and capacity utilisation while demand risks are caused by uncertainties in product demand over time.
Using flexible SC strategies can help prevent negative consequences of these risks [4, 12]. Table 2 indicates what specific strategies can be applied to manage different forms of SC risks (redrafted from the literature).

In case of multiple suppliers it is possible to place orders with those suppliers who offer the lowest cost. However, the maintenance of such wide supplier base may cause higher transaction costs which have also to be taken into account. This may be the case when using flexible supplier contracts: suppliers offering the possibility of quality or quantity revisions are in general more expensive due to additional availability costs.

Flexible manufacturing can be applied by companies producing multiple products. It is reasonable for them to build plants having the ability to manufacture more than one product. In this case the investment costs may be higher but the company will have the possibility to allocate production capacities in a flexible way according to customer demand. Customer demand may influence also product customisation. When the demand is uncertain it is worth postponing the last manipulations until customer needs are more visible. At the same time it may raise inventory costs, etc.

After analysing the application possibilities of SC risk reducing strategies we can conclude that the introduction of any measures shall be preceded by sound investigation of their costs and benefits. Controlling systems (see later) may help give a transparent picture of them. It is also important to note that most of risks originate mainly from demand uncertainties. That is why special attention shall be paid to demand management in supply chains.

\section{Demand management in supply chains}

Predictability of demand is a core factor of building effective supply chains. In case of general consumer products demand patterns are theoretically well known so here time series based methods can be successfully applied. However, in many industries customer needs are becoming rather irregular or lumpy, not to mention the so called hidden or latent demand. Here traditional forecasting techniques relying on past information can lead to high estimation error. A possible solution to that problem can be to make use of so called contextual information describing possible future actions (e.g. introduction of new policies, environmental factors, pricing regimes, etc.). It means that quantitative methods are to be combined with qualitative approaches so that estimation reliability increases [13].

So a typical demand forecasting procedure of a supply chain is recommended to include the following steps:

1 collecting time series data from the past;

2 de-seasonalising;

3 analysing trends;

4 extrapolating; 
Tab. 2. Strategies for reducing SC risks

\begin{tabular}{lll}
\hline $\begin{array}{l}\text { Risk types and } \\
\text { corresponding strategies }\end{array}$ & SC strategy & Mechanism of strategy \\
\hline Supply cost risks & Multiple suppliers & $\begin{array}{l}\text { More active suppliers and shifting orders across them } \\
\text { based on cost savings. }\end{array}$ \\
\hline Supply commitment risks & Flexible supplier contracts & $\begin{array}{l}\text { Shifting orders across time based on allowable } \\
\text { changes in quantity or quality. }\end{array}$ \\
\hline Process risks & Flexible manufacturing processes & $\begin{array}{l}\text { Shifting production quantities across plants by taking } \\
\text { plant capacities into account. }\end{array}$ \\
\hline Demand risks & Postponement & $\begin{array}{l}\text { Timing of procedures when generic semi-finished } \\
\text { products are customised into end products. }\end{array}$ \\
\hline
\end{tabular}

5 adding business intelligence (extra information on demand patterns derived from dedicated customer data bases or customer relationship management - CRM - tools);

6 adding contextual information;

7 correcting extrapolations;

8 seasonalising.

Customer data/relationship management is often not regarded as important business factor (yet). Companies tend to excel in cost efficient supply management and manufacturing processes rather than responding to customer needs quicker and better. They collect a large amount of data even on their clients but hardly make advantages of them while financial or accounting information are widely used for supporting decision making processes. Another problem is the poor quality of customer data. At the same time supply chains should be governed by reliable demand information. That is why more emphasis shall be given to effective use of state of the art data management and modelling techniques which enable to better understand customer behaviour [10].

We can conclude that an effective demand management in SC requires the application of up to date information technologies corresponding to the criteria identified before. These techniques (like data warehouse based data mining or CRM), however, are quite expensive so they can be used mainly by bigger companies. SMEs are able to use mainly simple (extrapolating) tools for demand estimation but it is advisable for them to correct the outcomes also by contextual factors as far as it is possible.

\section{Supply chain controlling}

The goal of supply chain controlling is to deliver appropriate information for decision making processes aiming to plan, evaluate or monitor certain logistics service networks. Several management tools are suitable to perform theses tasks. Here three of them - quick scan audit, process or activity based costing $(\mathrm{ABC})$, key performance indicators - are discussed.

The quick scan audit methodology (QSAM) assesses logistics service networks to find the key enablers for enhancing supply chain performance. It is a team based approach, relies on empirical findings and consists of six major steps [3]. Table 3 describes the basis of the methodology - adapted from the literature - according to these milestones.

The QSAM is a qualitative evaluation procedure using as much quantitative information as possible. It results in an action plan giving guidelines on where and how to intervene into the given SC to enhance its performance and effectiveness. But it is important to know the financial effects of intended process reengineering, too. Process or activity based costing can help answer such questions after adapting its methodology to logistics specifications. ABC corresponds more to the specific features of logistics than the traditional cost object based calculations does. Here cost objects are replaced by activities, which enables to depict cost and performance management procedures in a process oriented way. Initial implementation models of logistics $\mathrm{ABC}$ have already been elaborated [2].

The general requirements of logistics cost accounting systems can be summarised as follows [9]:

- appropriate cost allocation by exploring dependences of cost elements and cost drivers (certain performance indicators);

- cross department or company cost elements have to be also analysed;

- (performance related) variable and fixed cost items shall be differentiated to make distinction between short and long term decision making;

- semi fixed cost items - classified as non-variable element but can be adjusted at certain time intervals - shall be presented separately;

- commitment periods for semi fixed cost elements (time frames during which they are constant) shall be added;

- controlling information are to be provided on a direct as well as on a full cost basis (in the latter case: including indirect costs, too).

$\mathrm{ABC}$ (adapted to SC characteristics) fulfils the above mentioned criteria. Its application increases the transparency of logistics 
Tab. 3. The SC quick scan audit process

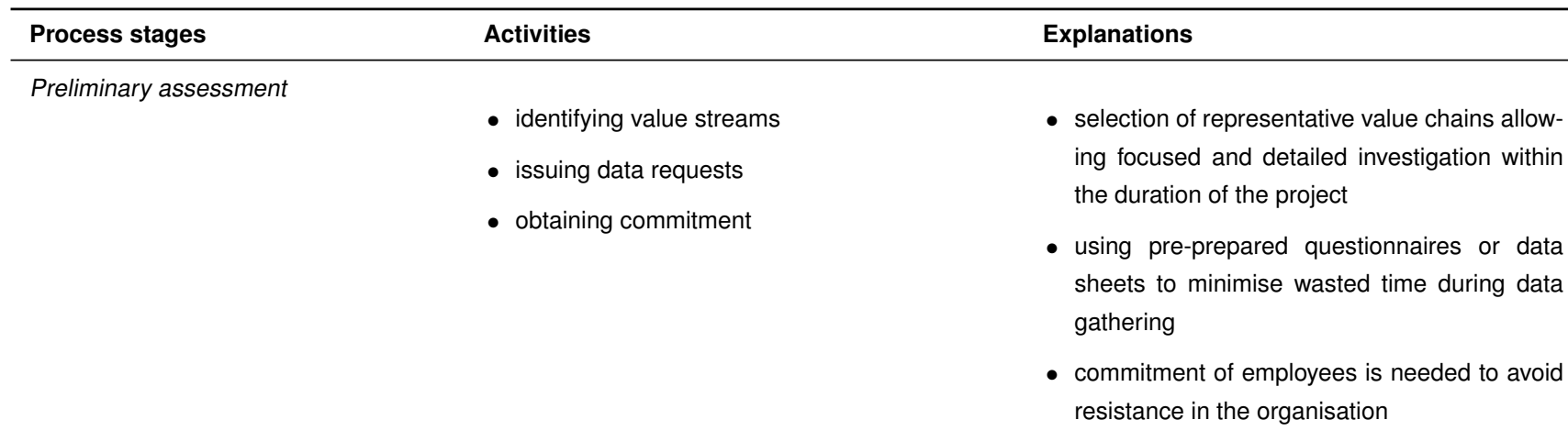

SC status evaluation

- collecting questionnaires

- conducting interviews

- building a process map
- data gathering is based on more sources which are harmonised so that bias is reduced significantly

- the process map describes the operation of selected supply chains in details

\section{Identification of SC inhibitors}

- identifying good/bad practices

- developing hypotheses

- identifying further data requests
- initial impressions are discussed within the team

- possible causes of bad practices are hypothesised

- additional data requests for validation of hypotheses are identified

\section{Investigation of hypotheses}

- collecting archival data

- conducting probing interviews

- observing current practise
- special time series are collected to test the hypotheses

- further interviews focus on why current practices are indifferent

- material and information flows are observed and documented with special regard to data shortages
- identifying major problems

- cause-effect analysis

- elaborating improvement opportunities
- over-ridding problems are first defined

- development of a detailed cause-effect diagram based around the major problems related to bad practices which identifies the root causes

- improvement opportunities for the root causes are elaborated and ranked by benefit, cost and time of implementation
Feedback

- presenting the findings

- initiating discussion

- agreeing on the action plan
- the goal is to understand the main shortcomings of the SC within the company and agree on the action plan to eliminate the most significant barriers 
costs in supply chains and helps charge these elements - as far as it is possible - to product/service objects which generate them. The implementation, however, requires additional (more detailed) data collection in the fields of activities, performance factors and accounting.

It is often the case when decision makers have to take decisions immediately or in a short time. Then the decisions rely on a limited set of key performance indicators. These indicators show the planned and actual values (including deviations) of most important factors influencing the operation or financial performance of the supply chain. The diagnostic function makes it possible to form a general opinion about the SC efficiency. However, if more insight into details is needed then drilling down along data hierarchies may be also necessary.

Empirical researches have resulted that focusing of management interventions on improving key performance indicators may lead to significant positive changes in company benefit [6].

\section{IT support for supply chains}

The best practice SC management methods described before can be implemented in an effective way only if a powerful IT background serving them can be put into operation.

Supply chains are facing several business challenges influencing also the functional and technological configuration of IT systems. The most important of them is enhancing the response mechanism (to customer demand or environmental changes, etc.). It requires seamless integration of design, production, commercialisation and forwarding. So the consolidation of diverse processes and systems is critical from the point of view of operational efficiency. Forming a robust IT strategy for supply chains and their participating partners may be a real solution to these challenges. A robust IT strategy determines the mix of applications that best serve the information needs as there is no one single solution that would fit all organisations [11].

Based on robust strategies so called service oriented IT architectures (SOA) are preferred in case of today's supply chains. SOA is a design philosophy for IT system structure. In this architecture functionalities of applications are modularised within strict standards. These modules can be utilised from other applications independent form the used technology. So an application developer can compose from the standardised modules dedicated IT solutions adapted to specific company needs. At the same time this composite solution can connect - due to the standardised interfaces - to required functionalities that are distributed along the SC partner systems. The diverse systems can run even in different platforms as SOA enables to create flexible shared information structure serving multiple players [8].

Using SOA based IT tools based on robust strategies contributes to make advantages of SCM best practices. The key prerequisite to it is standardisation. Another problem to be solved is information security. Shared data bases enable the SC partners to access each other's operational or even strategic information. It is necessary for planning and monitoring cross or- ganisational logistics processes. Nevertheless such kind of open systems shall be equipped also by regulation mechanisms governing access rights. It guaranties that each partner can see the set of information only which is indispensable for him and at the same time he is responsible for the actualisation of this data base regularly.

\section{Conclusions}

The analysis of selected SCM best practices shows that there is no a single set of tested tools for improving SC effectiveness and/or efficiency. Although the management models have already proven their viability by solving several business problems care must be taken before adopting them in a concrete case.

For example the level of SC integration shall be adjusted to the scope of activity area or the cooperation readiness of interested partners while using risk management techniques requires sound cost-benefit analysis. Demand management delivers key information for shaping supply chains but can be very expensive if supported by dedicated customer databases. SC controlling cover a vide variety of decision support methods which are recommended to be used only if the accounting system can be prepared for them. And at last but not least, IT is a core element of the practical implementation of the management methodologies. Open information architectures seem the most suitable to response the functional requirements set by SC operators.

More similar conclusions can be drawn in the future by conducting additional research in SCM practice.

\section{References}

1 Boehme T, Potter A, Childerhouse P, Corner J, Deakins E, The Development of a Generic Supply Chain Integration Model Using the Quick Scan Diagnostic Methodology, Proceedings of the 12th International Symposium on Logistics (Pawar K S, Lalwani C S, Muffatto M, eds.), Nottingham University Business School, Nottingham, 2007, pp. 202-208.

2 Bokor Z, Supporting Logistics Decisions by Using Cost and Performance Management Tools, Periodica Polytechnica ser. Transport Engineering, posted on 2008, DOI 10.3311/pp.tr.2008-1-2.07, (to appear in print).

3 Childerhouse P, Towill D. R, Boehme T, Deakins E, The Quick Scan Audit Methodology: a Supply Chain Diagnostic Approach, Proceedings of the 12th International Symposium on Logistics (Pawar K S, Lalwani C S, Muffatto M, eds.), Nottingham University Business School, Nottingham, 2007, pp. 195-201.

4 Cooper J C, Logistics Strategies for Global Businesses, Transport Logistics (McKinnon A, Button K, Nijkamp P, eds.), Edward Elgar Publishing Ltd, Cheltenham, 2002, pp. 16-27.

5 Henstra D, Ruijgrook C, Tavasszy L, Globalized trade, logistics and intermodality: European perspectives, Globalized freight transport (Leinbach T R, Capineri C, eds.), Edward Elgar Publishing Ltd., 2007, pp. 135-163.

6 Jánoshalmi T, Supply Chain Value Levers, SAP AG Business Consulting ANZ, 2007. Presentation.

7 Morash E A, Clinton S R, The Role of Transportation Capabilities in International Supply Chain Management, Transport Logistics (McKinnon A, Button K, Nijkamp P, eds.), Edward Elgar Publishing Ltd, Cheltenham, 2002, pp. 3-15.

8 Saha R, Goel A, Enabling Collaboration in Global Supply Chains Through Service Oriented Architecture (SOA), Proceedings of the 12th International 
Symposium on Logistics (Pawar K S, Lalwani C S, Muffatto M, eds.), Nottingham University Business School, Nottingham, 2007, pp. 402-205.

9 Siepermann C, Logistics Cost Accounting: Which System Is Best Suited?, Proceedings of the 12th International Symposium on Logistics (Pawar K S, Lalwani C S, Muffatto M, eds.), Nottingham University Business School, Nottingham, 2007, pp. 270-278.

10 Somani J. P, Narasimhan B, Sharma R, Customer Data Management - a Key Pre-requisite in Improving Supply Chain Efficiency, Proceedings of the 12th International Symposium on Logistics (Pawar K S, Lalwani C S, Muffatto M, eds.), Nottingham University Business School, Nottingham, 2007, pp. 209-214.

11 Sundararajan M. K, Venkataraman S, Narasimhan B, CPG Industry Formulating Robust IT Strategies to Tackle Supply Chain Dynamics, Proceedings of the 12th International Symposium on Logistics (Pawar K S, Lalwani C S, Muffatto M, eds.), Nottingham University Business School, Nottingham, 2007, pp. 11-16.

12 Tang C, Tomlin B, The Power of Flexibility for Mitigating Supply Chain Risks, Proceedings of the 12th International Symposium on Logistics (Pawar K S, Lalwani C S, Muffatto M, eds.), Nottingham University Business School, Nottingham, 2007, pp. 157-163.

13 Zwiep J, Planning in PCE, PHILIPS SC Academy, 2006. Presentation. 